\title{
Palyatif ve yaşam sonu bakım
}

\section{End of life and palliative care}

\author{
(D)Aydın Çifci \\ Kırıkkale Üniversitesi Tıp Fakültesi, İç Hastalıkları Anabilim Dalı, Kırıkkale, Türkiye
}

Cite this article as / Bu makaleye atıf için: Çifci A. Palyatif ve yaşam sonu bakım. J Med Palliat Care 2021; 2(1): 21-24.

\begin{abstract}
ÖZ
İnsanlar doğarlar, yaşarlar ve doğal olarak ölürler. Ölüm de hayatın bir gerçeğidir. Yaşam kalitesi, fiziksel, ruhsal, sosyal, duygusal yönden bireyin algıladığı iyi olma halidir. Kanser, ileri demans, immobilite gibi tam bir iyilik hali ve tam bir tıbbi tedavinin mümkün olmadığ 1 durumlarda, hastanın yaşam kalitesinin artırılması ve korunması palyatif bakımın temel hedefini oluşturmaktadır. Dünya Sağlık Örgütü tanımına göre palyatif bakım; kapsamlı bir değerlendirme ve tedaviyle hastalar tarafından yaşanan fiziksel, psikososyal ve manevi semptomların giderilmesini, aynı zamanda ailenin, arkadaşların, bakım verenlerin desteklenmesini ve acılarının hafifletilmesini amaçlar.
\end{abstract}

Anahtar Kelimeler: Palyatif bakım, yaşam sonu bakım, yaşam kalitesi

\begin{abstract}
People are born, live and naturally die. Death is also a fact of life. Quality of life is the state of well-being that the individual perceives physically, spiritually, socially and emotionally. Increasing and maintaining the quality of life of the patient is the main target of palliative care in case of complete wellness and medical treatment are not possible such as cancer, advanced dementia and immobility. According to the World Health Organization definition palliative care aims to relieve the physical, psychosocial and spiritual symptoms experienced by patients with a comprehensive assessment and treatment, as well as to support the family, friends and caregivers, and to alleviate their suffering.
\end{abstract}

Keywords: Palliative care, end of life care; quality of life

\section{GíRiş}

Palliate Latince kökenli ve koruyucu ya da kapsayıcı, İngilizce palliative ise terminolojide hafifletici, yatıştırıcı, geçici çare anlamında kullanılmaktadır. Yaşam kalitesi, fiziksel, ruhsal, sosyal, duygusal yönden bireyin algıladığı iyi olma halidir. Kanser, ileri demans, immobil hasta vs. gibi geri dönüşün ve tam bir iyilik hali, tam bir tıbbi tedavinin mümkün olmadığı durumlarda, hastanın yaşam kalitesinin artırılması/korunması palyatif bakımın temel hedefini oluşturmaktadır. Evet bazen hastada tam bir iyilik hali mümkün olmayabilir ama insanların ömrünün son dönemlerinin mümkün olduğunca konforlu geçirmesi çok önemlidir. Başta uzak organ metastazı yapmış kanserler olmak üzere pek çok başka duruma da bağlı olabilen kronik ağrı, düșkünlük, kronik beslenme bozukluğu bu problemlerin en başında gelmektedir.
Kronik problemlerin sonucu olarak genellikle yaşlı olan bu kesimde anksiyete, depresyon, ölüm korkusu, gibi pek çok psikiyatrik problem de gelişmektedir. Hayatı uzatmak önemlidir ama bunu yaşam kalitesini arttırarak yapmak daha da önemlidir ve palyatif bakım merkezleri de tam bu hedef için kurulmuştur. ABD'de kanser en sık ölüm nedenleri arasında ikinci sırada yer almaktadır. Dünya Sağlık Örgütü kanser yükünün 18,1 milyon yeni vakaya yükseldiğini ve 2018'de 9,6 milyon kişinin kanserden öldügünü raporlamıştır. Palyatif bakımın amacı; bireylerin toplumsal ve kültürel inanç ve değerlerine duyarlı kalınarak, hastalığa bağlı ortaya çıkan ağrı ve diğer semptomların hafifletilmesi ve yaşam kalitesinin artırılmasıdır (1-5) (Tablo 1). 
Tüm dünyada olduğu gibi ülkemizde her geçen gün nüfus yaşlanmakta ve palyatif bakım hizmetlerine gereksinim duyulan hasta sayısının artmaktadır. Bu durum palyatif bakım konusunda kapsamlı bir yapılanmaya gereksinim olduğunu göstermektedir $(2-4,7,8)$.

\section{DÜNYADA PALYATIIF BAKIM}

Palyatif ve yaşam sonu bakım hizmetleri başarılı hükümetler için bakım kalitesini artırmak ve yaşam sonu bakım maliyetlerini azaltmak amaciyla bir politika önceliği olmuştur. Bu sistemlerin entegre bir şekilde uygulanması bakım kalitesini, verimliliği, çalışan ve hasta memnuniyetini artırdığı gibi uluslararası bir öncelik olarak kabul edilmiştir. Dünya Palyatif Bakım İttifakı ve Dünya Sağlık Örgütü beş kıtadan sadece üçünde kaliteli palyatif bakım hizmeti sunulduğunu belirtmiştir (9-13).

\section{YÖNERGEDE TANIM}

"Palyatif Bakım Hizmetlerinin Uygulama Usul ve Esasları Hakkında Yönergesi” 2015 yılında yürürlüğe girmiştir (3). Amaç: Yaşamı tehdit eden hastalıkların getirdiği sorunlara bağlı olarak ortaya çıkan problemlerle karşılaşan hastalarda;

- Ağrı ve diğer semptomları erken tanımlamak ve değerlendirmek

- Hasta ve ailesine yönelik tıbbi, psikolojik, sosyal ve manevi destek vererek acılarını hafifletmek

- Hasta ve ailesinin yaşam kalitesini geliştirmek için faaliyet göstermek olarak tanımlanmıştır.

\section{TÜRKIYYE'DE PALYATİF BAKIMIN GELİŞİMI VE MEVZUAT}

Palyatif bakımın, tedavi seçeneklerinin azalması, genel durumun giderek kötüleşmesi, nütrisyon, ağrı ve diğer belirtilerin kontrolünün yetersiz kalması ve gerekli teknik desteğin sağlanamaması nedeniyle çoklu problemi olan hastalardaki önemi giderek artmaktadır. Palyatif bakım, hastanın pek çok problemine çözüm üretmeye çalışması ve süregelen ve altta yatan asıl patolojilerde genellikle kalıı bir düzelme sağlayamaması nedeniyle, yaşamın son dönemindeki hastanın kaliteli bakımının nasıl sağlanabileceği konusunda sıkıntı oluşturmaktadır. Ölmekte olan veya iyileşme ihtimali olmayan hastaya bakım vermek acı veren, üzüntülü bir deneyimdir ve hemşire korku, üzüntü, düş kırıklı̆̆ı, anksiyete gibi duygular hissedebilir. Palyatif bakımda hemşireden beklentinin karşılanabilmesi için, hemşirenin nitelikli bir eğitim ile yaşam sonu bakıma hazırlanması, yeterli kişiler arası iletişim becerilerine ve baş etme stratejilerine sahip olmasi gerekir. Hastalara daha iyi bir hizmet verilebilmesi için yönergede (bakınız "Palyatif Bakim Hizmetlerinin Uygulama Usul ve Esasları Hakkında Yönerge”) belirtilen fiziki şartlar ve donanımın belli asgari standartları karşılaması gerekmektedir (3,9,11,13-17).

SUT'ta palyatif bakım hizmetleri kapsamı aşağıda detaylı olarak verilmiştir (Tablo 1).

Palyatif bakımda hangi hasta grubu yatmalı? Hastaların değerlendirilmesi için kriterler Tablo 2 ve Tablo 3 'te belirtilmiştir.

Tablo 1. SUT'ta palyatif bakım hizmetleri kapsamı (3 no'lu kaynaktan uyarlanmıștır)

- Beslenmesi fiziksel ve psikolojik/nörolojik nedenlerle bozulup enteral, parenteral beslenme desteğine ihtiyaç duyanlar,

- Enfeksiyon, kas ve nörolojik hastalıklar nedeniyle solunumu bozulmuş olup, invaziv ve noninvaziv mekanik ventilasyon desteğine ihtiyacı olan hastalar,

- Enfekte yatak yarası açılan, ostomi bölgelerinde enfeksiyon, kaçak sorunları olan (trakeotomi, gastrostomi, ileostomi, kolostomi vs.), kateteri olup tıkanan, kırılan, giriş yeri enfeksiyonu olan ya da katetere bağlı fonksiyon bulguları bulunan (diyaliz kateteri, santral venöz kateteri, şant kateterleri, ağrı portu ve kateteri, perkütan plevral kateter, perkütan mesane kateteri) hastalarının tedavisi ve tıbbi sorunlarının giderilmesi.

Tablo 2. Başvuru sırasında palyatif bakım ihtiyacını değerlendirme kriterleri (6 no’lu kaynak)'den uyarlanmıştır.

Potansiyel Hayatı Sınırlayıcı ya da Hayatı Tehdit Eden Durum ve ...

\section{Pimer Kriterler}

"Sürpriz soru": hasta 12 ay içinde ya da yetişkinliğe geçmeden ölseydi şaşırmazdınız

Sık başvuru (Aynı hastalık nedeniyle birkaç ayda birden fazla başvuru )

Kontrol edilmesi güç fiziksel ya da psikiyatrik semptomlar nedeniyle başvuru (24 saatten 48 saate kadar artan, moderate ya da ağır semptom şiddeti)

Kompleks bakım ihtiyaçları (fonksiyonel bağımlılık: ventilatörlantibiyotiklbeslenme gibi kompleks ev destekleri)

Fonksiyon kaybı, beslenme intoleransı, kiloda amaçlanmamıș kayıp (örn. kilo alamama)

\section{Sekonder Kriterler}

Uzun süreli bakım tesisinden ya da tıbbi koruyucu evden kabul edilmiş olmak,

Kognisyonu hasarlı, akut kalça kırığı olan, yaşlı hasta

Ende kronik oksijen kullanımı olan hasta

Hastane dişı kardiyak ölüm

Şu anda ya da geçmişte tedavi edilemez hastalığa yönelik hizmet programında yer almış olmak

Limitli sosyal destek (örn; ailede stres, kronik zihinsel hastalık)

Geçmişte hiçbir ileri bakım sorgulaması|dosyası doldurmamış olmak 
Palyatif bakımda yatan hastaların hangi durumda yatırılacağı, hangi durumda taburcu edilebileceği ile ilgili kriterler belirlenmeye çalışılmıștır (Tablo 4, 5) $(3,9$, 15,18-23).

\section{SONUÇ}

Dünya nüfusunun giderek yaşlanmaktadır, bu da palyatif bakım ihtiyacının giderek artacağını göstermektedir. Palyatif bakımda seçilecek hedefler ve tedaviler hastaya özgül olmalı, sistematik bir bütüncül yaklaşım olmalı ve klinisyenin tecrübelerini içermelidir. Ülkemizde palyatif bakımın ayrı bir uzmanlık alanı olması, multidisipliner hizmet sunabilecek palyatif bakım merkezleri sayesinde gereksiz yoğun bakım yatışlarının önlenmesi, sağlık çalışanlarının mezuniyet öncesi ve sonrası eğitim programları ile desteklenmesi, çocuk palyatif bakım merkezlerine yönelik düzenleme yapılması, palyatif bakım hizmetlerinin ülke genelinde birinci, ikinci ve üçüncü basamak arasında entegre bir şekilde yürütülmesi için politikaların belirlenmesi, gönüllülerin ve sivil toplum kuruluşlarının sürece dahil edilmesi, ülkemizin sosyokültürel ve yaşam biçimine uygun hospis çalışmalarının başlatılması önerilmektedir.

\section{Tablo 3. Palyatif bakım değerlendirmesi için NCCN Kriterleri (8 no'lu kaynaktan uyarlanmıştır)}

\begin{tabular}{|c|c|}
\hline Hasta özellikleri & Hasta kaybina neden olabilecek sosyal durum ve olaylar \\
\hline Tedavi için sınırlı seçeneklerin olması & Bakıma sınırlı ulaşım \\
\hline $\begin{array}{l}\text { Kötü ağrı kontrolü ya da refrakter ağrı için yüksek risk. Risk faktörleri: } \\
\text { · Nöropatik ağrı } \\
\text { · Kaçak ağrı ya da olay ağrısı, } \\
\text { · Opioid dozunun hızlı yükseltilmesi } \\
\text { · Madde kullanımı öyküsü(örn. ilaç, alkol) } \\
\text { · Hasarlı kognisyon } \\
\text { · Psikososyal/ailesel stres }\end{array}$ & $\begin{array}{l}\text { Ailevi faktörler: } \\
\text { - Ailelbakıcının sınırlamaları } \\
\text { · Yetersiz aile desteği } \\
\text { - Aile anlaşmazlığı } \\
\text { - Aşırı bağımlı ilişkililişkiler öyküsü }\end{array}$ \\
\hline Yüksek semptom yükü ya da distres skoru & Finansal kisitlamalar \\
\hline $\begin{array}{l}\text { Multipl komplikasyonlarla ya da uzamış ventilatör ihtiyacı ile yoğun bakım } \\
\text { ünitesine kabul edilmiş olmak }\end{array}$ & Çözümlenmemiş yas ya da çoklu önceki kayıplar \\
\hline Konvansiyonel yönetime refrakter olan ağrı dışındaki fiziksel semptomlar & Manevi ya da egzistansiyalist (varoluşçu) krizler \\
\hline Kognitif hasar & \\
\hline Ağır ya da çoklu komorbid durumlar & \\
\hline Konuşulan dil, okur yazarlık ya da fiziksel konular nedeniyle iletişim bariyerleri & \\
\hline Hızlandırılmış ölüm isteği & \\
\hline
\end{tabular}

\section{Tablo 4. Ülkemizde palyatif bakım ünitesine kabul kriterleri}

Yatağa bağımlı, küratif tedavisi olmayan, fiziksel ve emosyonel semptomların kontrol edilmesinde güçlük yaşanan, başkasının desteğine ihtiyacı olan hastalar palyatif bakım ekibi tarafından değerlendirilir. Yatırılarak bakım verilmesinin, kişiye veya ailesine yararlı olacağına karar verilen hastaların yatışı sağlanır.

- Medikal tedaviye rağmen VAS (Visual Analogue Scale) ağrı skalası $\geq 5$ olan, ağrıya bağlı uyku düzeni bozulan, istirahatta dahi ağrısı devam eden ve yan etkiler nedeni ile medikal tedavi uygulanamayan hastalar,

- Oral alımı bozulmuş, NRS 2002 (Nutritional Risk Screening 2002) beslenme skoru $\geq 3$ olan, son 6 ay içerisinde \%10’dan fazla kilo kaybı olan, hiç oral alamadığı için enteral ya da parenteral beslenme desteğine ihtiyaç duyan malnutrisyonlu hastalar,

- Enfekte ve/ veya tedaviye dirençli, Evre III- IV (Norton/ Braden’a göre) dekübit yarası olan hastalar,

- Deliryum tanısı almış, etiyolojisi çoklu veya belirsiz olan hastalar,

- Geriatrik Sendromlar: düşme, inkontinans, ihmal ve kötüye kullanım vb. olan hastalar,

- Tedaviye dirençli, evre IV kalp yetmezliği olan frajil hastalar,

- Tedaviye rağmen klinik ve laboratuvar olarak kötüleşen ve semptomları artan (dispne, hemoptizi, kontrol edilemeyen ağrı vb.) Karnofsky performans skoru <\%70 olan, vertebra metaztazı, hiperkalsemi gibi onkolojik acilleri olan, son 3 ay zarfında 2 defadan fazla pnömoni geçiren, komorbiditesi yüksek, beklenen yaşam süresi 6 aydan kisa, cerrahi, radyoterapi (RT) ve kemoterapi (KT) gibi tedavilere rağmen progressif hastalığı olan onkoloji hastaları,

- Kronik, tedaviye dirençli olan son dönem akciğer hastaları,

- Klinik tablosunda akut değişiklik olan demans hastaları: FAST (Functional Assesment Staging of Alzheimer's Disease) Sınıflandırılmasına göre Evre 7 ve üzeri olan ve günlük aktivelerinin en az üç tanesini yardımla yapabilen hastalar,

- Kronik nörolojik hastalığı olup (hipoksik iskemik ensefalopati, inme, Parkinson hastalığı, amiyotrofik lateral skleroz, multipl skleroz vb. klinik tablosunda akut değişikliği olan (ateş, beslenme bozukluğu, dekübit yarası, üriner enfeksiyonlar, pnömoni, öz bakımlarında azalma vb.) hastalar,

- Tükenme sendromuna girmiş son dönem HIV hastaları

Taburculuk planlanmasının amacı; sürekli bakım için bir çerçeve oluşturmak ve hastanın bir ortamdan daha uygun bir ortama geçişini kolaylaştırmaktır. Taburculuk multidisipliner bir süreçtir ve sürdürülmesi tüm ekibin ortak ve açı iletişimine bağlıdır. Taburculuk planlanmasında; hasta ve ailesinin tüm kararlara katılımı konusunda bilgilendirilmesi ve aydınlatılmış onamının alınması gereklidir. 


\section{ETİK BEYANLAR}

Hakem Değerlendirme Süreci: Harici çift kör hakem değerlendirmesi.

Çıkar Çatışması Durumu: Yazar(lar) bu çalışmada herhangi bir çıkara dayalı ilişki olmadığını beyan etmişlerdir.

Finansal Destek: Yazar(lar) bu çalışmada finansal destek almadıklarını beyan etmişlerdir.

Yazar Katkıları: Yazarların tümü; makalenin tasarımına, yürütülmesine, analizine katıldığını ve son sürümünü onayladıklarını beyan etmişlerdir.

\section{KAYNAKLAR}

1. Lederberg MS, Joshi N. End-of-life and palliative care. In Kaplan \& Sadock's Comprehensive Textbook of Psychiatry, 8th edition (Eds BJ Sadock, VA Sadock):2336-2365. Baltimore, Lippincott Williams \& Wilkins, 2005.

2. Makary M, Daniel M. Medical error-the third leading cause of death in the US. BMJ 2016; 353: i2139.

3. Palyatif Bakim Hizmetlerinin Uygulama Usulve Esasları Hakkında Yönerge [Erișim Tarihi 2015] https://dosyamerkez.saglik.gov.tr/ Eklenti/2817,palyatif-bakim-hizmetleri-yonergesipdf.pdf?0

4. OkonTR Arnold RM GivensJ Overview of comprehensive patient assessment in palliative care. UpToDate Nov 02, 2018.

5. Zadeh RS, Eshelman P, Setla J, Sadatsafavi H. Strategies to improve quality of life at the end of life: interdisciplinary team perspectives. Am J Hosp Palliat Care 2018; 35: 411-6.

6. Weissman DE, Meler DE. Identifying patients in need of palliative care assessment in the hospital setting. J Palliat Med 2011; 14: 17.

7. WHO, International Agency for Research on Cancer. Latest global cancer data 2018.

8. Levy MH, Adolph MD, Back A, et al. Palliative care. J National Comprehensive Cancer Network 2012; 10: 1284-309.

9. Palyatif Bakım Evde ve Hastanede Çalıştay Raporu. T.C. Sağlık Bakanlığı Türkiye Kamu Hastaneleri Kurumu. İzmir Kuzey Kamu Hastaneleri Birliği Genel Sekreterliği. Tepecik Eğitim ve Araştırma Hastanesi. Ege Geriatri Derneği Yayınları No:1. 2013.

10. Reville B, Foxwell AM. The global state of palliative care-progress and challenges in cancer care. Ann Palliat Med 2014; 3: 129-38.

11.Özçelik H. Kanser Hastasının Palyatif Bakımında Vaka Yönetimi Modelinin Hasta Sonuçlarına Etkisinin İncelenmesi. Doktora Tezi, Ege Üniversitesi Sağlık Bilimleri Enstitüsü, İzmir; 2011.

12. Davies JM, Sleeman KE, Leniz J, et al. Socioeconomic position and use of healthcare in the last year of life: a systematic review and meta-analysis. PLoS Med 2019; 16: e1002782.

13. Aslan Y. Türkiye'de ve Dünya'da palyatif bakım modellerine genel bakış. Anadolu Güncel Tip Derg 2020; 2: 19-27.

14. Buss MK, Lessen DS, Sullivan AM, Von Roenn J, Arnold RM, Block SD. Hematology/oncology fellows' training in palliative care: results of a national survey. Cancer 2011; 117: 4304-11.

15. Gültekin M, Özgül N, Olcayto E, Tuncer AM. Türkiye'de palyatif bakim hizmetlerinin mevcut durumu. Türk Jinekolojik Onkoloji Derg 2010; 13: 1-6.

16. Payne DK, Massie MJ. Anxiety in palliative care. In: Handbook of Psychiatry in Palliative Medicine, Chochinov HM, Breitbart W (Eds), Oxford University Press, New York 2000. p.435.

17. Hunter J, Orlovic M. End of life care in England. Institude for Public Policy Research. A Breefing Paper. 2018.
18. Kabalak AA, Öztürk H, Cağıll H. Yaşam sonu bakım organizasyonu; palyatif bakım. Yoğun Bakım Derg 2013; 11: 56-70.

19. Estella A, Velasco T, Saralegui I, et al. Multidisciplinary palliative care at the end of life of critically ill patient. Med Intensiva 2019; 43: 61-2.

20.Cruz-Oliver DM. Palliative-care: an update. Missouri Medicine 2017: 114: 110-5.

21. Uslı FŞ; Terzioğlu F. Dünyada ve Türkiye’de Palyatif Bakim Eğitimi ve Örgütlenmesi. Cumhuriyet Hemşirelik Derg 2015; 4: 81-90.

22. Payne S, Eastham R, Hughes S, Varey S, Hasselaar J, Preston N. Enhancing integrated palliative care: what models are appropriate? A cross-case analysis. BMC Palliative Care 2017; 16: 64.

23. Hunter J, Orlovic M. End of life care in England. Institude for Public Policy Research. A Breefing Paper. 2018. 